Article

\title{
Regional Transport Indicators Used in Sweden for Measurement, Reporting and Verification of $\mathrm{CO}_{2}$ Emissions
}

\author{
Kerstin Robertson ${ }^{1, \dagger, *}$, Annika Jägerbrand ${ }^{2, \dagger}$ and Jan R. Eriksson ${ }^{1, \dagger}$
}

1 Swedish National Road and Transport Research Institute, SE-581 95 Linköping, Sweden;

E-Mail: jan.eriksson.vti@gmail.com

2 Swedish National Road and Transport Research Institute, Box 55685, SE-102 15 Stockholm, Sweden; E-Mail: annika.jagerbrand@vti.se

$\dagger$ These authors contributed equally to this work.

* Author to whom correspondence should be addressed; E-Mail: kerstin.robertson@vti.se; Tel.: +46-13-20-42-02; Fax: +46-13-14-14-36.

Academic Editor: Andreas Manz

Received: 20 November 2014 / Accepted: 8 April 2015 / Published: 15 April 2015

\begin{abstract}
Established practice is available as a reference for evaluating sustainable transport and $\mathrm{CO}_{2}$ emissions at national, European and global levels, but comparing corresponding systems at the regional and local levels are more challenging. Therefore, this paper analyses the use of indicators, evaluation methods and data availability at local and regional levels for applied policies and measures in transport planning. Sweden is used as a case study. Available data show that total surveys (e.g., vehicle registry data), sample surveys (e.g., interviews) or modelling can be used to develop transport indicators, and that either generated (volume generated in the area) or performed (volume in the area) traffic and transportation is estimated. However, there are limitations with all methods and the design of evaluations needs careful consideration in order to reflect changes in local and regional transport systems and to relate those changes to specific measures and policies. In most cases, survey methods need to be used in order to follow up the most common indicators. All evaluation methods need to be complemented with analyses of a baseline to determine additionality and also potential rebound effects need to be considered, which requires the application of a wider systems perspective.
\end{abstract}


Keywords: traffic; local; regional; evaluation; carbon dioxide emissions; decoupling; transport planning

\section{Introduction}

Large increases in transport activities are anticipated to occur in the future, especially in underdeveloped countries, and transport is continuously increasing globally [1]. Several sustainability problems are associated with increased transport activities, for example congestion, increased dependence on fossil fuels, traffic safety issues and increased environmental impacts. Transport contributes $25 \%-30 \%$ of global energy-related carbon dioxide $\left(\mathrm{CO}_{2}\right)$ emissions and is therefore a significant contributor to total greenhouse gas (GHG) emissions [2,3]. Worldwide transport energy use and $\mathrm{CO}_{2}$ emissions are projected to increase by nearly $50 \%$ by 2030 and by more than $80 \%$ by 2050 [3]. For example, trucking, air transport and car ownership have the potential to increase three- or four-fold relative to current levels. Consequently, transport is a particularly challenging issue for planners and policymakers aiming to achieve a stable, sustainable development.

In order to evaluate the efficiency of measures and activities intended to reduce transport and its negative consequences, systems and methods for measurement, reporting and verification (MRV) are required. Established practise is available for measuring transport activities and $\mathrm{CO}_{2}$ emissions at national, European and global levels, but there is a lack of corresponding systems at the regional and local level. For example, many countries have binding obligations to reduce their GHG emissions within the commitment periods of the Kyoto Protocol (initiated by the United Nations Framework Convention on Climate Change, UNFCCC), and report their emissions in National Inventory Reports [4,5]. In Europe, the European Environment Agency (EEA) produces an annual report (Transport and Environment Reporting Mechanism, TERM) to provide "a clear overview of current transport demand, the pressures from the transport sector on the environment, and related impact and responses" [6]. The 2013 report provided an overview by monitoring 12 TERM Core Set of Indicators (TERM-CSIs) of transport activities and environmental impacts for the European Union (EU) and at the Member State level [6].

The use of indicators at local and regional level involves some difficulties and challenges that are largely related to determining cause and effect of measures and implemented transport policies for the resulting transport demand and development. In particular, measures and policies aimed at shifting travel demand to more sustainable transport modes require parameters that are difficult to quantify and interpret [7]. Examples of measures and policies used locally and regionally with the aim of reducing transport system problems such as congestion and environmental effects are: Promotion of public transport (PT), bicycle use, use of alternative fuels and/or vehicles, regulations and economic instruments, and development of new infrastructure. Furthermore, there is a need to manage the transport system, understand it, measure it and detect e.g., transport patterns or demands characterising a specific geographical area that are not visible in agglomerated data on the national level.

Evaluations of transport measures and policies are therefore challenging and often require complex sets of data and information about traffic volumes, the relative use of different types of transport modes, 
vehicles and fuels, and information on shifts in modal split. This paper focuses on defining the concept of local and regional transport indicators based on mapping of available data, using Sweden as a case study. The possibilities and obstacles relating evaluation to local and regional transport policies, measures, and indicators are analysed and discussed. The emphasis is on developing and using road and rail traffic and transportation indicators based on the availability of quantitative data at the local and regional scale, covering both passenger and goods traffic and transportation. The work is a part of a project examining methodologies for $\mathrm{MRV}$ of $\mathrm{CO}_{2}$ effects of transport activities.

\section{Local and Regional Traffic and Transportation Indicators}

The concept of indicators needs to be placed in context in order to be understood and used correctly [8]. Traffic and transport indicators are a specific example of a comprehensive system with established (when possible) terms and definitions.

Indicators of local and regional traffic and transportation can be based on different types of data and information, depending on the scope and objective of the evaluation. Absolute data, such as complete registry data, are used in the first instance, but when this alternative is not available sample surveys may be an alternative. Combinations of absolute data and sample surveys are frequently used to develop indicators.

In some cases, indicators need to be based on model calculations. One reason for this may be that the cost of obtaining survey data is too high. Different data and information collection strategies are described in Section 3, but first some basic concepts of indicators in general, and traffic and transportation indicators in particular, are described below. Also defined here are performed and generated traffic and transportation.

\subsection{Indicators as a Concept}

The concepts and definitions used here are mainly based on the information pyramid (see e.g., [9]). The information pyramid base is data, which often consists of huge amounts of data elements that need to be processed and/or aggregated before being interpreted and used to draw general conclusions. This processing or compilation results in indicators that make up the next level of the pyramid. Indicators describe the data sufficiently well to allow detailed analysis. More extensive aggregation (i.e., processing or summarising) of the data produces key indicators, which represent the next level in the information pyramid. The top level of the pyramid consists of the index values, the overall level where further aggregation of the data is impossible. The index can thus be viewed as a first description of information obtained using the data contained in the information pyramid. There are also other definitions of the indicators and the information pyramid. For example, data can be separated into raw data and structured data, databases and/or statistics. Index values, key indicators and indicators can sometimes be collectively referred to as indicators. However, the definition of indicator used in this text is that described above.

The general use of indicators is motivated by the need to aggregate data and information in order to use it in different contexts, such as local and regional planning and evaluation of policies and measures. 


\subsection{System Boundaries}

Local and regional traffic and transportation can be provided on a national, regional, county or local level. The focus here is to propose indicators that can be used at local and at county level (i.e., regional level). However, it is important to consider possible agreement with corresponding indicators of both higher and lower resolution (measure/project and national level, respectively).

Area-specific traffic and transport indicators can in principle be defined in two ways: (i) as the traffic and transportation carried out or performed in the area; or (ii) the traffic and transportation generated by organisations and residents in the area. Thus, local and regional traffic and transportation can be either:

- performed local or regional traffic or transportation (volume in the area);

or

- generated traffic or transportation (volume generated in the area).

Performed local and regional traffic and transportation is commonly used in the conventional definition of local and regional traffic and transportation. A problem with this definition is that no statistics are available for calculating the indicators, because the traffic to, from and through (transit) a region must be allocated to within or outside that region. Thus for this form of allocation, traffic models must be used.

Generated local and regional traffic and transportation is performed by residents and businesses in the area, but need not be actually performed within the region. Indicators can in principle be calculated using only statistical local and regional data, which can be supplemented by simple models. In general practice, the indicators of generated local and regional traffic and transportation are calculated using only statistical data.

The higher the resolution, the greater the differences between the indicators of performed and generated traffic and transportation may be. This is due to the fact that with decreasing area size, the share of intra-area traffic and transportation decreases and the proportion of traffic to, from and through an area increases, but this also depends on characteristics of the specific area.

The type of indicator (performed or generated) most suitable for use in evaluations of effects on local and regional traffic and transportation may depend on the type of measure or policy introduced. To evaluate the effects of infrastructure measures or policies in the form of e.g., improved roads or modified traffic control, indicators of performed regional traffic and transport work are recommended, since the effects include all traffic in the area. However, if the effects of local or regional mobility management are being evaluated, the generated regional traffic and transport work would be preferable for use as a transport indicator. This is because the measure, in this case mobility management, is aimed at all residents and businesses in the region, and the effects may extend outside the region. The best indicator to use needs to be decided in each specific case, but some general guidelines are presented below.

\section{Traffic and Transportation Data}

Data and information available in Sweden are used below as the basis for evaluations and for calculating the values of local and regional traffic and transportation indicators in three different approaches: Absolute data and information, sample surveys and modelling. 


\subsection{Absolute Data and Information}

Absolute data and information can be obtained from surveys or registers and include all data and information about the study object. This has the advantage that there is in principle no restriction on the ability to group the data, for example geographically.

\subsubsection{National Road Database}

The Swedish Road Database includes all public and private roads and streets in Sweden, including the bicycle network [10]. The database includes a range of informative data such as: Lengths of different types or categories of streets, roads and networks, road width, surface quality, presence of railings etc. The data can be extracted for the whole network and/or for specified geographical areas.

\subsubsection{National Vehicle Registry}

The Swedish Vehicle Registry includes all vehicles registered in Sweden and provides great opportunities for analysing and processing, e.g., time series [11,12]. The data (on Swedish registered vehicles) available are: Brand, model, colour, weight class, year of first registration, current status (in traffic, off road), commercial use, fuel type, engine power, type of body, number of axles, number of passengers, displacement (applies only to motorcycles and cars), imported or originally registered in Sweden, owner's age, gender, business branch, county/region, municipality, postal code, change of ownership, and environmental class.

These basic data can be used for evaluating traffic generated locally or regionally, based on the geographical location of vehicle ownership.

\subsubsection{National Vehicle Inspection Registry}

The Swedish Vehicle Inspection Registry, based on the annual road worthiness tests at the Swedish vehicle inspection centres, contains information about driving distances for all tested vehicles (cars, buses, lorries, motorcycles), whether they passed the inspection or not and whether the vehicle is in traffic [13]. Statistical information is published annually [14].

Using vehicle inspection data in combination with data from the Swedish Vehicle Registry, it is possible to calculate average mileage for traffic generated per year and area or region for different categories of vehicles. However, these data do not include information about where the vehicle was driven. Moreover, some correction of the data is required regarding new vehicles, especially cars, which do not require inspection during their first three years. Other possible data biases are imported vehicles and off-road notifications.

\subsubsection{Public Transport Data}

Data and information about travelling by publicly procured local and regional public transport (PT), the dominant form in Sweden, are collected annually from the PT providers [15]. Travel by bus, train, tram, metro and ferry is included. The data include information on e.g., number of trips (boardings), 
passenger-kilometres and supply (vehicle-kilometres and seat-kilometres). Comprehensive statistics for special public transport (e.g., school buses) and for tourist and charter services are also available.

Data reliability is highly related to how well different variables are defined, described and understood. Quality control is also essential. The fact that local and regional PT (road and rail) is publicly procured in Sweden means that these statistics are publicly available. However, in some cases commercial actors are also involved and statistics are usually not available for these cases. These data represent performed travelling volumes and cannot be allocated to residents in a specific region.

Annual statistics on rail traffic include the number of journeys, quantity of goods and transport performance (passenger- and tonne-kilometres) per year at the national level [16]. Data on local and regional level are not publically available.

\subsection{Sample Surveys}

Sample surveys are carried out as random sampling in some form. The surveys collect small numbers of elements, which are assumed to be representative for the entire population. The representativeness of this type of data needs to be based on sound statistical analysis. If the sample survey includes sufficient elements it is possible to group the material obtained, e.g., into groups of common geographical affiliation, even if the original survey was not stratified for this purpose.

\subsubsection{Travel Surveys}

Travel surveys (TS) designed to deliver statistically significant results are one means to evaluate travel habits, requirements, trends and the use of different modes for passenger transport. The Swedish national travel survey includes: People's daily travel, time at which the journey was undertaken, transport mode used and reason for the trip [17]. Data on travel patterns provide important background information for the design of national and regional traffic policies, development of infrastructure and transport services, road safety efforts and for research and development on people's travel and communication patterns. The TS include the Swedish population aged 6-84 years and are carried out as telephone interviews.

Travel surveys are carried out at approximately five-year intervals in Sweden. However, the level of travel cannot be directly compared between the different TS due to some methodological differences. Moreover, the sample size usually does not allow for local and regional evaluations.

Local and regional travel surveys (LRTS) may be performed by different municipalities in order to determine the travel habits and requirements of their residents and to evaluate the frequency of use of different travel modes (modal split) (e.g., [14]). However, there is no common strategy or methodology for LRTS, so the possibility to compare results and data from consecutive travel surveys or surveys from different areas may be limited.

Although TS are methods with high potential for evaluating traffic and transportation generated in a specific area, they are labour-intensive and there is also a high risk of misinterpretation of the results. Travel surveys are complex and the raw data must be carefully aggregated into indicators, which need to be defined and explained. There may also be problems associated with gathering the information and possible biases caused by missing data. Statistical analysis is crucial in order to avoid using non-significant results. 


\subsubsection{Road Freight Survey}

Official national statistics on domestic and international road freight transport with Swedish-registered vehicles are collected and published annually [18]. The survey includes Swedish registered lorries, tractors and towing vehicles with a maximum load weight of 3.5 tonnes or more. These are investigated through a continuous survey in which about 12,000 vehicles from a total of about 56,000 are included annually. The most important variables describe: Kilometres driven, amount of loaded goods and performed tonne-kilometres, and haulage. Some of the variables in the study are: Truck registration number, year of model, kerb weight, loading location, unloading location, kilometres driven, description of goods, goods weight, goods tonnes-kilometres, and percentage cargo volume utilisation (optional).

The reliability of these data, which represent generated national road freight, is strongly dependent on the frequency of replies from the carriers and on the quality of the data reported. Swedish Transport Analysis, the authority responsible for the national road freight statistics has noted that the data from the survey can be based on underestimations. Thus, the general validity and quality of the road freight data can be questioned. Corresponding data are not available locally or regionally. Data on rail freight are only publically available on national level.

\subsubsection{Traffic Flow Data}

Traffic flow measurements are carried out nationally on the Swedish road network, in a continuous schedule [19]. A few roads have been monitored year-round for a number of years, but for many of the roads monitored a random sampling strategy is applied for a shorter period only. Different types of vehicles can be distinguished in these measurements, but numbers of passengers and loading data are not registered.

Traffic flow measurements can also be made locally and regionally, but such measurements are entirely dependent on the motives and interests of the local or regional authority. Flow measurements may also be used for bicycle counts, whereas new techniques must be used if the aim is to count pedestrians.

The possibility to extrapolate from traffic flow measurements to local or regional performed traffic is highly dependent on the statistical base for the design of the measurements and may vary considerably. In order to calculate transportation based on traffic flow counts, load factors data are also required.

\subsection{Model Calculations}

Various types of models are used to produce data on traffic and transportation. In the models, conditions such as income, population and infrastructure are used as inputs, and the resulting output describes future changes in traffic (e.g., number of vehicles or vehicle-kilometres) and future demand for travel and freight transport in order to identify where traffic and transport will occur [20]. Models may be used both for estimating performed and generated traffic and transportation.

\subsubsection{Traffic and Transportation Modelling}

As a complement to absolute and sample data, modelling is used for calculating the effects of different measures and policies on national, regional and local passenger traffic and transportation and for developing forecasts of future traffic and transportation. The Swedish national model system 
(SAMPERS) comprises a set of submodels and is primarily used for long-term effects and forecasts, not for yearly evaluations. Databases include the road and rail networks, car ownership and information from the national travel survey (start and end point, route, modal choice) [21]. The reliability of model output is highly related to the quality of the input data, the quality of the relationships used in different submodels and the assumptions applied, e.g., regarding future growth. Depending on the model used, either generated or performed traffic and transportation can be addressed.

Freight traffic and transportation is modelled on the national level. The model SAMGODS [22] can currently only be used for national analyses of e.g., the consequences of policy and infrastructure development, traffic analyses and economic assessments. The distribution of goods locally and regionally may be addressed in policies and strategies to develop more efficient distribution systems. However, there is no common tool (model) available for evaluations.

Locally, different models are used, depending on the specific requirements in each individual case. Some examples are traffic assignment and traffic flow models that are used for evaluating effects of development and dimensioning of new infrastructure.

\subsubsection{Fuel Consumption and $\mathrm{CO}_{2}$ Emissions}

Emissions of $\mathrm{CO}_{2}$ from traffic can be based either on top-down or bottom-up calculations or modelling [23], depending on the objective. Top-down calculations are based on aggregated data or statistics and average emission factors, and can be used e.g., for estimations of national emissions or for assessing the credibility of bottom-up calculations. Bottom-up calculations are based on detailed information about emission sources and allow evaluation of local measures and policies, provided that relevant information about the sources (e.g., emissions factors for different types of vehicles) is available. Bottom-up calculations result in $\mathrm{CO}_{2}$ emissions generated by vehicles registered locally or regionally, while top-down calculations result in $\mathrm{CO}_{2}$ emissions performed in the area.

Details of the mileage driven per year are available from the Swedish Vehicle Inspection Registry for all tested vehicles (see above). The method involves using the kerb weight, engine power and fuel, producing information on petrol and diesel consumption generated by traffic and transportation by vehicles registered locally or regionally.

This information may benefit from being compared with sales statistics in order to evaluate the calculated (modelled) fuel consumption and also to evaluate the use of alternative fuels, such as ethanol, biogas and electricity. However, sales statistics are not generally available locally or regionally.

\section{Discussion}

A wide range of traffic and transportation indicators are used for different purposes. National traffic and transport indicators, which also correspond to local and regional objectives, have been proposed by the EEA [6]. It suggests using its 12 TERM-CSIs to assess key trends and overall progress (Table 1). 
Table 1. List of the Transport and Environmental Reporting Mechanism Core Set of Indicators (TERM-CSIs) suggested by the European Environmental Agency (EEA).

\begin{tabular}{cc}
\hline No. & Indicator \\
\hline 1 & Transport final energy consumption by mode. \\
2 & Transport emissions of greenhouse gases. \\
3 & Transport emissions of air pollutants. \\
4 & Exceedances of air quality objectives due to traffic. \\
5 & Exposure to, and annoyance by, traffic noise. \\
6 & Passenger transport volume and modal split \\
7 & Freight transport volume and modal split. \\
8 & Real changes in transport prices by mode. \\
9 & Fuel tax rates. \\
10 & Energy efficiency and specific $\mathrm{CO}_{2}$ emissions. \\
11 & Share of renewable energy in the transport sector. \\
12 & Proportion of vehicle fleet by alternative fuel type. \\
\hline
\end{tabular}

In addition, the following seven local and/or regional transport indicators have been developed and have been proposed by Statistics Sweden [24] (Table 2).

Table 2. Seven transport indicators that can be applied at municipal or regional level.

\begin{tabular}{cc}
\hline No. & Indicator \\
\hline 1 & Car ownership per 1000 inhabitants. \\
2 & Cars by environmental category in total or proportion of new registrations. \\
3 & Proportion of green cars in stock and relative to new registrations. \\
4 & Average mileage per car \& year, and average mileage per car \& capita \& year \\
5 & Proportion of heavy/strong and weak/light cars. \\
6 & Petrol and diesel consumption, litres per kilometre and for a standard car. \\
7 & Petrol and diesel consumption per car \& year and per inhabitant \& year. \\
\hline
\end{tabular}

Some additional common goals evaluated using indicators, besides reduced $\mathrm{CO}_{2}$ emissions, are accessibility, reliability, comfort, safety and security [25,26].

Policies and measures aimed at more $\mathrm{CO}_{2}$-efficient local and regional traffic and transportation that may need to be followed up using indicators which typically focus on the following areas $[27,28]$ :

- Modal split (bicycling, walking, use of public transport, car use)

- Use of alternative vehicles and renewable fuels

- Traffic and transportation energy efficiency and $\mathrm{CO}_{2}$ emissions

Some examples of policies and measures commonly used are mobility management (promotion of alternative transport modes), infrastructure development, economic instruments, improved PT, parking policy, and local and regional planning aimed at sustainable urban development. There is consequently a need for MRV of the effects of a wide variety of policies and measures.

The data availability for MRV of local and regional passenger traffic and transportation is discussed below. Data interpretation in relation to baseline levels and rebound effects [29] is also addressed. Baseline denotes the traffic and transportation development that would have taken place without the 
specific policy or measure evaluated. For example, economic growth usually results in increased traffic and transportation that may need to be used as a baseline for evaluation and interpretation of data. Rebound effects are effects that counteract the desired effects of policies and measures. The use of e.g., less energy-consuming cars may lead to longer driving distances, resulting in less energy than anticipated being saved. The availability of freight data on local and regional level is very limited and is therefore not discussed further.

\subsection{Modal Split (Bicycling, Walking, Use of Public Transport, Car Use)}

As indicated above, there are many types of policies and measures that may be used for promoting modal shift, ranging from mobility management and development of PT to parking policy and infrastructure development. In general, there are no absolute data that reflect transportation by different modes locally and regionally. The most robust method for evaluating modal split is therefore to use LRTS, provided they are based on sound statistics (Table 3). LRTS provide data about the whole transport system and include all modes, which is important when assessing baseline changes and possible rebound effects.

Table 3. Main data sources for different categories of indicators. The most suitable data source for each transport indicator is indicated in italics.

\begin{tabular}{|c|c|c|c|}
\hline Indicator $\backslash$ Data & Absolute Data & Sample Surveys & Modelling \\
\hline Modal split & $\begin{array}{c}\text { Vehicle registry } \\
\text { Vehicle inspection } \\
\text { Public transport data }\end{array}$ & $\begin{array}{l}\text { Travel surveys } \\
\text { Traffic flow data }\end{array}$ & Passenger traffic and transportation \\
\hline $\begin{array}{l}\text { Alternative vehicles } \\
\text { and renewable fuels }\end{array}$ & $\begin{array}{c}\text { Vehicle registry } \\
\text { Vehicle inspection } \\
\text { Public transport data }\end{array}$ & Travel surveys & Fuel consumption \\
\hline $\begin{array}{l}\text { Energy efficiency } \\
\text { and } \mathrm{CO}_{2} \text { emissions }\end{array}$ & $\begin{array}{c}\text { Vehicle registry } \\
\text { Vehicle inspection } \\
\text { Public transport data }\end{array}$ & Travel surveys & $\begin{array}{c}\text { Fuel consumption } \\
\mathrm{CO}_{2} \text { emissions }\end{array}$ \\
\hline
\end{tabular}

LRTS may be complemented by PT statistics, but the use of such statistics needs to be carefully considered, since it is often not clear whether an increase should be attributed to a modal shift from private cars or from bicycling and walking. Improved PT and increased travelling by PT may also lead to increasing distances between residential and work areas, which is a type of rebound effect [29]. In addition, economic growth may result in increased PT baseline travelling.

Local or regional use of private cars (generated traffic) may also be evaluated using vehicle registry and vehicle inspection data (driving distances). In order to extrapolate to transportation, however, the number of passengers also needs to be known (and can be obtained from LRTS). This information should also be related to general baseline development.

Vehicle flow counts can be designed statistically to reflect the whole transport system, but this is not very common. Flow counts and modelling are primarily used for evaluating the traffic load on different streets or roads. In order to use flow data for evaluations of policies and measures, the connection to the specific street or road needs to be carefully considered and other causes of possible flow changes need to be analysed. 
While LRTS provide data about traffic and transportation generated with vehicles owned locally or regionally, flow counts do not distinguish between vehicles and delivery traffic performed in the area. Modelling may be used for estimating performed modal split, but models are primarily used for developing forecasts. Model-based evaluations are also very uncertain.

\subsection{Use of Alternative Vehicles and Renewable Fuels}

Information on the vehicle composition in a local or regional area can be obtained from vehicle registry data and on driving distance from vehicle inspection data (Table 3). Data on the number of cars or vehicles that can run on renewable fuels or electricity, and their driving distances, are available for evaluations of traffic generated by vehicles based in a particular area, but there is still uncertainty regarding the actual fuel use, since the majority of alternative cars are hybrids.

Fuel use or consumption data are not available from these databases, however, and are usually not available locally or regionally, since this is not publically available information. Consequently, assumptions usually need to be made about the actual use of alternative fuels. Again, LRTS are the most reliable source of information about the use of alternative vehicles and fuel use. The use of alternative fuels can possibly be extrapolated from national data, depending on whether the geographical distribution of the consumption is known.

Statistics on the use of alternative vehicles and fuels may be available for publically procured PT, but all the data in question represent generated traffic and transportation. In order to obtain performed traffic and transportation data, modelling is required.

When using alternative vehicles and renewable fuels as an indicator, it is important to consider that rebound effects may influence the trends over time in unknown ways. For example, subsidies for environmental cars may result in lower driving costs, which in turn may result in additional mileage due to increased usage [29,30]. Furthermore, with e.g., an actual increase in numbers of vehicles, a baseline needs to be defined in order to distinguish the proportion related to changing from conventional cars and fuels to alternative cars and renewable fuels and the proportion representing an actual increase of the vehicle fleet in the area studied.

\subsection{Traffic and Transportation Energy Efficiency and $\mathrm{CO}_{2}$ Emissions}

Traffic energy efficiency can be estimated as fuel consumption per vehicle-kilometre and transportation energy efficiency as fuel consumption per passenger-kilometre. For evaluations of energy efficiency and $\mathrm{CO}_{2}$ emissions from vehicles based locally or regionally, vehicle registry and vehicle inspection data can again be used for determining mileage for different categories of vehicles. Information on numbers of passengers and fuel use needs to be obtained from LRTS.

Emissions of $\mathrm{CO}_{2}$ need to be calculated or modelled from these data in combination with emissions factors for different categories of vehicles. Since the calculations are based on vehicle registry data, the evaluations represent generated traffic and transportation. Possible rebound effects relate to the risk of increasing mileage due to the lower energy consumption (and cost), and a mileage baseline is required for evaluations. 


\subsection{Generated and Performed Traffic and Transportation}

Data for estimating generated local or regional traffic and transportation are available, whereas assessments of performed traffic and transportation need modelling approaches. Modelling involves more assumptions and the variability in the results usually increases.

Depending on the objective and scope of the evaluation, the most relevant systems limit may be either generated or performed local or regional traffic and transportation. In many cases generated traffic and transportation is the most relevant, for example when measures and policies relate to residents in the specific area. For evaluations of $\mathrm{CO}_{2}$ effects, generated traffic and transportation may be adequate, although performed traffic and transportation would also be relevant. For other environmental effects acting more locally, such as emissions to air, noise and, possibly, congestion, performed traffic might be the most relevant systems limit. The systems limit applied must be decided from case to case, and it should always be clearly specified.

\subsection{Baseline and Rebound Effects}

In order to distinguish an effect, or additionality, of a specific measure or a certain policy on local and regional traffic and transportation, a baseline needs to be defined. However, this is a delicate task, since there are always multiple transport measures and policies acting on the transport system simultaneously. In addition, there are also measures and policies in other planning sectors that affect the transport system. Moreover, effects occur over time, making it necessary to adjust the baseline in relation to economic growth, as increasing transport is often closely linked with general economic growth.

The need for transport in a region is linked to the regional economy (labour market, businesses, etc.) and infrastructure. In order to monitor trends in transport relative to economic development in a region, total or different modes of (generated) transport relative to the regional gross domestic product (GDPR) can be used. It is important to compare against a given year when studying the changes over time (from year to year) within each region.

However, the relationship between traffic/transportation and economic growth may be weakening. In recent EEA studies, decoupling (i.e., economic growth will not cause a corresponding increase in transport) has been used to assess freight transport demand (CSI 036/TERM 013) and passenger transport demand (CSI 035/TERM 012) [31,32]. On the basis of available data, it should be possible to apply decoupling at local or regional levels.

Rebound effects are the difference between anticipated/projected energy savings and the real energy savings from implemented measures or policies [33]. There may even be backfire effects of measures and policies when the improved energy efficiency results in an increased total energy demand. It is therefore important to consider and control rebound effects when monitoring or analysing effects in the transport system, e.g., environmental car policies or subsidies may result in increased use of vehicles or transport, yielding a net increase in transport and traffic demand [29]. The rebound effect may therefore lead to unwanted and indirect effects on travelling behaviour or energy consumption as a result of policies or subsidies implemented to reduce the overall transport demand. However, few studies have analysed rebound effects on local and regional levels and there is a lack of empirical evidence of rebound effects, especially within transport and community planning. Rebound effects for passenger vehicles 
have been suggested to be around $10 \%-30 \%$ in Sweden, but countries with a large unmet demand for energy may have substantially higher rebound or backfire effects.

\section{Conclusions}

This paper describes various aspects and challenges of the currently used and proposed transport indicators and MRV available for monitoring and assessment of policies and measures in applications on local and regional scales. All methods referred have some limitations and the design of MRV therefore needs careful evaluation in order to reflect changes in local and regional transport systems and to relate those changes to specific measures and policies.

MRV of "improve" strategies, for example aiming at exchanging presently used cars with more sustainable alternatives, can be based on vehicle registry and inspection data. MRV of the use of alternative fuels and $\mathrm{CO}_{2}$ emissions, however, needs additional survey-based data collection (LRTS). Similarly, "shift" strategies, aiming at a more sustainable modal split, need to be based on LRTS, and consequently the evaluations address traffic and transportation generated in the area under study. Vehicle flow counts and transport modelling are primarily used for planning purposes and the development of scenarios, and have limited value as MRV instruments. We therefore conclude that there are no robust methods for evaluating and validating traffic and transportation performed in a defined geographical area. Further, in all cases referred to, a baseline needs to be defined in order to demonstrate additionality, i.e., effects of specific measures and policies.

In conclusion, evaluation of local and regional transport systems, and transport measures and policies is highly dependent on the design and implementation of LRTS, and there are only robust methods for evaluating "generated" traffic and transportation. However, evaluations using LRTS also need to consider the risk for rebound effects, which calls for the application of a wider systems perspective.

\section{Acknowledgments}

We gratefully acknowledge financial support from the Swedish Energy Agency's Climate Policy Research Programme, project number 35446-1.

\section{Author Contributions}

Kerstin Robertson and Jan Eriksson came up with the idea for the paper and Kerstin Robertson, Annika Jägerbrand and Jan Eriksson drafted the manuscript. All authors read, commented and approved the final manuscript.

\section{Conflicts of Interest}

The authors declare no conflict of interest. 


\section{References}

1. Ribeiro, K.S.; Kobayashi, S.; Beuthe, M.; Gasca, J.; Greene, D.; Lee, D.S.; Muromachi, Y.; Newton, P.J.; Plotkin, S.; Sperling, D.; et al. Transport and its infrastructure. In Climate change 2007: Mitigation. Contribution of Working Group III to the Fourth Assessment Report of the Intergovernmental Panel on Climate Change; Metz, B., Davidson, O.R., Bosch, P.R., Dave, R., Meyer, L.A., Eds.; Cambridge University Press: Cambridge, UK, 2007.

2. OECD and ITF. Reducing Transport GHG Emissions. Opportunities and Costs. Preliminary Findings of the OECD/ITF Working Group on Transport GHG Emissions Reduction StrategiesReport to be Released 2010; The Organisation for Economic Co-operation and Development (OECD): Paris, France, 2009.

3. International Energy Agency and OECD. Transport, Energy and $\mathrm{CO}_{2}$. Moving towards Sustainability. Available online: http://www.iea.org/publications/freepublications/publication/ transport2009.pdf (accessed on 10 April 2015).

4. UNFCCC: Kyoto Protocol Annex B. Available online: http://unfccc.int/kyoto_protocol/ items/3145.php (accessed on 10 April 2015).

5. UNFCCC: National Inventory Submissions 2014. Avilable online: http://unfccc.int/ national_reports/annex_i_ghg_inventories/national_inventories_submissions/items/8108.php (accessed on 10 April 2015).

6. European Environment Agency. A Closer Look at Urban Transport-Term 2013: Transport Indicators Tracking Progress Towards Environmental Targets in Europe; European Environment Agency: Copenhagen, Denmark, 2013; pp. 1-106.

7. Romero, J. NAMAs, CDM and MRV: The Case of Transport Sector; Institute for Global Environmental Strategies: Hayama, Japan, 2012.

8. Hagnell, A.; Träff, Y. Miljöindikatorer-Ett stöd $i$ miljöarbetet; Sveriges Kommuner och Landsting: Stockholm, Sweden, 2007. (In Swedish)

9. Segenstam, L.; Persson, Å. Index, Indikatorer, Presentationsverktyg Och de Svenska Miljömålen; Naturvardsverket: Stockholm, Sweden, 2002. (In Swedish)

10. Swedish Transport Administration: Välkommen till nvdb på webb. Avilable online: https://nvdb2012.trafikverket.se/ (accessed on 10 April 2015). (In Swedish)

11. Swedish Transport Agency: Vägtrafikregistret Available online: https://www.transportstyrelsen.se/ sv/Vagtrafik/Fordon/Vagtrafikregistret/ (accessed on 10 April 2015). (In Swedish)

12. Transport Analysis: Statistics. Available online: http://www.trafa.se/en/Statistics/ (accessed on 10 April 2015).

13. Swedish Vehicle Inspection: Bilprovningens Besiktningsstatistik. Available online: http://www.bilprovningen.se/Om-Bilprovningen/Pressrum/Statistik.html (accessed on 10 April 2015). (In Swedish)

14. Niska, A.; Nilsson, A.; Wiklund, M.; Ahlström, P.; Björketun, U.; Söderström, L.; Robertson, K. Methods for Estimating Pedestrian and Cycle Traffic. Survey and Quality Assessment; Report 686; The Swedish National Road and Transport Research Institute: Linköping, Sweden, 2010. 
15. Transport Analysis: Lokal och regional kollektivtrafik. Available online: http://www.trafa.se/ sv/Statistik/Kollektivtrafik-och-samhallsbetalda-resor/Lokal-och-regional-kollektivtrafik/ (accessed on 10 April 2015). (In Swedish)

16. Transport Analysis: Rail traffic. Available online: http://www.trafa.se/en/Statistics/Rail-transport/ (accessed on 10 April 2015).

17. Transport Analysis: Travel survey RVU. Available online: http://www.trafa.se/en/Statistics/ Travel-survey-RVU/ (accessed on 10 April 2015).

18. Transport Analysis: Swedish national and international road goods transport. Available online: http://www.trafa.se/en/Statistics/Road-traffic/Domestic-and-international-transport-by-Swedish-lorries/ (accessed on 10 April 2015).

19. Swedish Transport Administration: Vägtrafik- och hastighetsdata Available online: http://www.trafikverket.se/Foretag/Trafikera-och-transportera/Trafikera-vag/Verktyg-e-tjanster-ochvagdata/Vagtrafik--och-hastighetsdata/ (accessed on 10 April 2015). (In Swedish)

20. Swedish Transport Administration: Samhällsekonomisk analys. Available online: http://www.trafikverket.se/Foretag/Planera-och-utreda/Planerings--och-analysmetoder/

Samhallsekonomisk-analys-och-trafikanalys/Analysmetod-for-samhallsekonomisk-effektivitet/ (accessed on 10 April 2015). (In Swedish)

21. Swedish Transport Administration: Sampers. Available online: http://www.trafikverket.se/ Foretag/Planera-och-utreda/Planerings--och-analysmetoder/Samhallsekonomisk-analys-ochtrafikanalys/

Prognos--och-analysverktyg/Fliksida---verktyg/Sampers/ (accessed on 10 April 2015). (In language)

22. Swedish Transport Administration: Samgods. Available online: http://www.trafikverket.se/ Foretag/Planera-och-utreda/Planerings--och-analysmetoder/Samhallsekonomisk-analys-ochtrafikanalys/

Prognos--och-analysverktyg/Fliksida---verktyg/Samgods/ (accessed on 10 April 2015). (In Swedish)

23. Swedish Transport Administration: Handbok för vägtrafikens luftföroreningar. Available online: http://www.trafikverket.se/Privat/Miljo-och-halsa/Halsa/Luft/Dokument-och-lankar-om-luft/Handbokfor-vagtrafikens-luftfororeningar/ (accessed on 10 April 2015). (In Swedish)

24. Beräkningsmodell för Bensin Respektive Diesel Förbrukning per Kommun. Available online: http://www.scb.se/Statistik/TK/_dokument/Anv\%C3\%A4ndarhandledning2011.pdf (accessed on 10 April 2015). (In Swedish)

25. Transport Analysis. Indikatorer för en Transportpolitisk Måluppföljning-Hur Tillgänglighet Påverkar Konkurrens-Och Utvecklingskraft; Trafikanalys Rapport: Torsgatan, Stockholm, 2013. (In Swedish)

26. Transport Analysis. Uppföljning av de Transportpolitiska Målen; Trafikanalys Rapport: Torsgatan, Stockholm, 2014. (In Swedish)

27. Commission of the European Communities. Towards a New Culture for Urban Mobility; Green paper; Brussels 25.9.2007, COM (2007) 551 Final; Commission of the European Communities: Brussels, Belgium, 2007.

28. Antagen av kf. Klimatplan för Eskilstuna; Eskilstuna kommun: Eskilstuna, Sweden. Available online: http://www.eskilstuna.se/PageFiles/193374/Klimatplan\%20KF\%202012-1213.pdf?epslanguage $=$ sv (accessed on 10 April 2015). (In Swedish) 
29. Jägerbrand, A.K.; Dickinson, J.; Mellin, A.; Viklund, M.; Dahlberg, S. Rebound Effects of Energy Efficiency Measures in the Transport Sector in Sweden; VTI Report; Swedish National Road and Transport Research Institute: Linköping, Sweden, 2014.

30. Kågeson, P. Dieselization in Sweden. Energ. Policy 2013, 54, 42-46.

31. EEA: Freight Transport Demand (CSI 036/TERM 013)_Assessment Published December 2013. Available online: http://www.eea.europa.eu/data-and-maps/indicators/freight-transport-demandversion-2/assessment-3 (accessed on 10 April 2015).

32. EEA: Passenger Transport Demand (CSI 035/TERM 012)_Assessment published December 2013. Available online: http://www.eea.europa.eu/data-and-maps/indicators/passenger-transportdemand-version-2/assessment-3 (accessed on 10 April 2015).

33. Winebrake, J.J.; Green, E.H.; Comer, B.; Corbett, J.J.; Froman, S. Estimating the direct rebound effect for on-road freight transportation. Energ. Policy 2012, 48, 252-259.

(C) 2015 by the authors; licensee MDPI, Basel, Switzerland. This article is an open access article distributed under the terms and conditions of the Creative Commons Attribution license (http://creativecommons.org/licenses/by/4.0/). 